\title{
Is combined rather than single antibiotic therapy actually reasonable in patients with acute calculous cholecystitis?
}

\author{
Ümit Alakuşs * (1), Yaşar Subutay Peker ${ }^{1}$
}

\begin{abstract}
SUMMARY
OBJECTIVE: Acute calculous cholecystitis (AC) is a frequently encountered emergency surgery disease and its standard treatment is cholecystectomy. In patients with high risk in surgery, antibiotic treatment (AT) is important. In routine clinical practices, antibiotics are frequently used either as single or in combination in the treatment of AC. This study examined whether or not combined antibiotic treatment (CAT) had superiority over single antibiotic treatment (SAT) in AC.

METHODS: Patients with cholecystitis who received treatment in the period of 2016-2019 were retrospectively examined. The treatment procedures applied, patient findings, and laboratory data were analyzed using relevant statistical software. The patients were categorized into groups based on the treatment approaches applied, and the effects of SAT and CAT on infection parameters were analyzed.

RESULTS: In all, 184 patients received treatment for AC, with a mean age of 57.7, and the female-to-male ratio was 77:107. Of these, 139 patients received SAT and 45 received CAT. No significant difference was found in terms of effectiveness between the SAT and CAT in the patients who received early cholecystectomy treatment and those who received medical treatment with noninvasive intervention. CONCLUSIONS: In patients with AC, antibiotics are commonly used either as single or in combination for prophylaxis and therapeutic purposes. As no significant difference was observed between single and combined use in terms of treatment effectiveness and hospitalization duration, CAT is not recommended due to its possibility of allergic side effects, toxicity, and cost-increasing effects.

KEYWORDS: Acute calculous cholecystitis. Antibiotic therapy. Cholecystectomy.
\end{abstract}

\section{INTRODUCTION}

Acute calculous cholecystitis (AC) is a serious infection that generally occurs as a result of a gallstone in the cystic duct or Hartmann's pouch blocking the drainage of bile. However, the process continues, with the participation of anaerobic and aerobic bacteria, especially Gram-negative microorganisms. Based on the severity of the infection, $\mathrm{AC}$ was classified into three groups, namely, Grade I: mild; Grade II: moderate; and Grade III: severe according to the Tokyo Guidelines ${ }^{1}$.

The standard treatment of AC cases is cholecystectomy. However, especially in patients with severe infection, in order to treat the infection and increase the success of surgical treatment, various antibiotics that are known to be effective on the biliary system are prevalently applied in the preoperative or postoperative period. Many studies have emphasized that bacteria do not have a significant effect in Grade I AC and that the antibiotic treatment (AT) that is applied does not change the prognosis of the patient, whereas AT needs to be applied in Grade II and Grade III cases $^{2-4}$. In empirical AT to be applied in AC cases, there are no precise standards regarding the type of antibiotic, dose of application, and application time. However, TG13 and TG18 provide various recommendations for empirical AT based on the severity of the infection ${ }^{5}$.

\footnotetext{
'University of Health Sciences, Gulhane Education and Research Hospital, Department of General Surgery - Ankara, Turkey.

*Corresponding author: umitalakus@yahoo.com

Conflicts of interest: the authors declare there is no conflicts of interest. Funding: none.

Received on June 19, 2021. Accepted on July 03, 2021.
} 
Antibiotic combinations that are not applied with an appropriate indication, at an appropriate dose, and for an appropriate duration not only increase the development of resistance but also bring about some allergic and toxic side effects. For this purpose, detailed recommendations were provided in the Tokyo Guidelines, and most centers have started to apply treatment procedures that are in compliance with these guidelines ${ }^{1}$. A study with broad participation which investigated changes in the treatment approaches of surgeons after the Tokyo Guidelines reported a significant decrease in the practice of combined antibiotic usage 5 .

The present study aimed to group patients with AC based on the AT that was applied, assess the effectiveness of single antibiotic treatment (SAT) and combined antibiotic treatment (CAT), and determine whether or not CAT had significant superiority over SAT.

\section{METHODS}

Patients who visited our clinic in the period of 2016-2019 with $\mathrm{AC}$ were examined. Changes in hematological parameters were checked in the beginning and at the end of the treatment and compared with hospitalization durations.

The patients who underwent early cholecystectomy were included in Group I, those who were given nonoperative minimally invasive interventions like endoscopic retrograde cholangiopancreatography (ERCP) and percutaneous cholecystostomy were included in Group II, and those who were given only medical treatment and given appointments for 6-8 weeks later for delayed cholecystectomy were included in Group III. The data were analyzed by dividing each group into two subgroups as SAT or CAT. The WBC (white blood cell), HGB (hemoglobin), PLT (platelet), \% NE (neutrophil), INR (international normalized ratio), CRP (C-reactive protein), ALT (alanine aminotransferase), AST (aspartate aminotransferase), GGT (gamma glutamyl transferase), ALP (alkalinephosphatase), amylase, total bilirubin, and direct bilirubin values measured in the beginning and at the end of the AT and hospitalization durations were analyzed using statistical program. The data were tested for normal distribution. While only the HGB data were normally distributed, other data were non-normally distributed. For statistical analysis, Student's t-test and Mann-Whitney $U$ test were applied. A $p<0.05$ was accepted as statistically significant.

\section{RESULTS}

In this study, 184 patients, with a mean age of 57.7 years, received treatment for AC. The most common symptoms associated with $\mathrm{AC}$ were epigastric upper right quadrant abdominal pain, nausea, vomiting, and mild fever. The most frequently encountered systemic comorbid diseases were diabetes mellitus and hypertension. Physical examination and laboratory findings were compatible with AC. Radiologically, in addition to the presence of stones or mud in the gallbladder, findings such as wall thickening and pericholecystic fluid collection were also observed. In addition, blood analysis shows an increase in infection markers such as WBC, CRP, and \%NE, as well as liver enzymes.

After the diagnosis of AC independently of the treatment option projected for the patients, penicillin-based AT with beta-lactamase inhibitors or AT including cefazolin, cefoperazone, and ceftriaxone was started. Forty-five patients received CAT including ertapenem, imipenem, or meropenem or including levofloxacin and ciprofloxacin with metronidazole. Penicillinbased treatment such as ampicillin/sulbactam was not given to any patient. In patients with severe sepsis findings, in a way to cover Gram-negative, Gram-positive, and anaerobic microorganisms, the combination of ampicillin+cephalosporin+metronidazole or the combination of piperacillin+tazobactam+metronidazole or the combination of imipenem+metronidazole was frequently preferred.

On the days following AT, laparoscopic cholecystectomy (LC) was applied in the low-risk patients, nonoperative interventions like ERCP and percutaneous cholecystostomy were applied on the high-risk patients with more severe infection findings, or in the patients responding well to antibiotic+supplementary medical treatment, appointments were given 6-8 weeks later for delayed cholecystectomy. Group I included 83, Group II included 23, and Group III included 78 patients, whereas 139 patients were given SAT and 45 patients were given CAT. Out of 63 patients in the early cholecystectomy group, 60 (95\%) received LC and $3(5 \%)$ received open cholecystectomy, while $55(93 \%)$ out of 59 patients in the delayed cholecystectomy group received LC and $4(7 \%)$ received open cholecystectomy.

The mean age of the patients who were given SAT was 57.3 years and that of those who were given CAT was 57.7 years, and there was no statistically significant difference between the two groups. The female-to-male ratio was 60:79 in the SAT group and 17:28 in the CAT group. The duration of hospitalization varied between 2 and 26 days, and the mean duration was 7.8 in both the groups. When all patients were compared based on their hospitalization durations in Groups I, II, and III and the SAT and CAT groups within these groups, no significant difference was found ( $\mathrm{p}=0.807, \mathrm{p}=0.723, \mathrm{p}=0.759, \mathrm{p}=0.813$ ).

The distributions of the WBC, HGB, PLT, \%NE, INR, CRP, ALT, AST, GGT, ALP, amylase, total bilirubin, and direct 
bilirubin values of the patients at visit to the hospital and at discharge based on their SAT or CAT status and their changes according to all patient group, Group I, Group II, and Group III are presented in Tables 1-3.

When the laboratory values were compared between the first admission and discharge times, although there was a significant reduction in the infection parameters in all patients, in the comparison made based on single or combined antibiotic usage, the difference was significant only in the ALT values in Group I and the ALT, INR, and \%NE values in Group III. There was no significant difference based on any parameter between the SAT and CAT in Group II. The patients in all groups were ultimately discharged with full recovery and without any morbidity.

\section{DISCUSSION}

The gold standard treatment in AC is LC, and the treatment plan should be established based on the general state of the patient, their comorbidities, and the degree of cholecystitis. In the initial treatment plan for patients who have clinical symptoms and findings, 4-5 days of AT with fluid electrolyte replacement has an important place ${ }^{6}$. It is recommended that early LC is appropriate in Grade I AC and that antibiotics should be used before surgery or during surgery rather for prophylactic purposes. There are many studies suggesting that antibiotic application in the postoperative period is not necessary in these patients ${ }^{4,7,8}$.

In elderly patients and those with poor general status who have severe AC findings, the risk of operative mortality is high due to organ dysfunctions. It is recommended to treat these patients with the appropriate medical treatment and antibiotic support using less invasive interventions like ERCP or percutaneous cholecystostomy instead of surgery ${ }^{9,10}$. The benefits of antibiotics and these minimally invasive interventions are limited, and the requirement of surgery arises in some of these patients. Especially in surgeries to be performed on patients who had percutaneous cholecystostomy, laparoscopic intervention becomes difficult due to pericholecystic adhesions, and therefore open cholecystectomy is performed in most cases.

According to some meta-analysis results, there was no significant difference in the treatment outcomes of patients who were given AT and those who were not given AT in AC and therefore antibiotic use is completely unnecessary ${ }^{11}$. However, it is recommended in guidelines to apply broad-spectrum antibiotics that are known to be effective on biliary system infections empirically for certain durations and at certain doses with fluid electrolyte treatment, and this treatment procedure

Table 1. Distribution of white blood cell, hemoglobin, platelet, neutrophil, international normalized ratio, C-reactive protein, alanine aminotransferase, aspartate aminotransferase, gamma glutamyl transferase, alkalinephosphatase, amylase, total bilirubin, and direct bilirubin values of patients in the cholecystectomy-applied group (Group I) ( $n=83$ ) based on their single or combined antibiotic treatment status.

\begin{tabular}{|c|c|c|c|c|c|c|c|c|}
\hline \multirow{2}{*}{$\begin{array}{l}\text { Laboratory } \\
\text { results }\end{array}$} & \multicolumn{3}{|c|}{ Single antibiotic $(n=63)$} & \multicolumn{3}{|c|}{ Combined antibiotic $(n=20)$} & \multirow{2}{*}{$\begin{array}{l}\text { Difference } \\
\text { between } \\
\text { changes }\end{array}$} & \multirow[b]{2}{*}{ p-value } \\
\hline & $\begin{array}{l}\text { First value } \\
\text { (mean) }\end{array}$ & $\begin{array}{l}\text { Last value } \\
\text { (mean) }\end{array}$ & $\begin{array}{l}\text { Change } \\
\text { (mean) }\end{array}$ & $\begin{array}{l}\text { First value } \\
\text { (mean) }\end{array}$ & $\begin{array}{l}\text { Last value } \\
\text { (mean) }\end{array}$ & $\begin{array}{l}\text { Change } \\
\text { (mean) }\end{array}$ & & \\
\hline $\mathrm{WBC}\left(/ \mathrm{mm}^{3}\right)$ & 14.53 & 10.05 & 4.48 & 12.90 & 11.10 & 1.80 & 2.68 & 0.33 \\
\hline Hemoglobin ( $\mathrm{g} / \mathrm{dL})$ & 13.41 & 11.66 & 1.75 & 13.54 & 11.92 & 1.62 & 0.13 & 0.75 \\
\hline PLT (/dL) & 270.56 & 306.05 & -35.49 & 264.70 & 312.40 & -47.70 & 12.21 & 0.73 \\
\hline$\% N E$ & 76.29 & 67.52 & 8.77 & 79.33 & 71.72 & 7.61 & 1.16 & 0.30 \\
\hline INR & 3.51 & 3.09 & 0.42 & 1.22 & 1.34 & -0.12 & 0.54 & 0.31 \\
\hline CRP & 137.33 & 95.28 & 42.05 & 108.97 & 69.54 & 39.43 & 2.62 & 0.94 \\
\hline ALT & 53.97 & 42.06 & 11.91 & 80.90 & 29.60 & 51.30 & -39.39 & 0.03 \\
\hline AST & 43.67 & 37.11 & 6.56 & 53.55 & 35.20 & 18.35 & -11.79 & 0.99 \\
\hline GGT & 97.63 & 77.98 & 19.65 & 193.05 & 79.75 & 113.30 & -93.65 & 0.13 \\
\hline ALP & 98.63 & 94.52 & 4.11 & 114.70 & 85.60 & 29.10 & -24.99 & 0.16 \\
\hline Amylase & 66.51 & 60.63 & 5.88 & 225.75 & 65.70 & 160.05 & -154.17 & 0.44 \\
\hline Bilirubin total & 1.04 & 0.64 & 0.40 & 1.93 & 0.86 & 1.07 & -0.67 & 0.37 \\
\hline Bilirubin direct & 0.35 & 0.22 & 0.13 & 0.76 & 0.25 & 0.51 & -0.38 & 0.87 \\
\hline
\end{tabular}

WBC: white blood cell; PLT: platelet; \%NE: neutrophil; INR: international normalized ratio; CRP: C-reactive protein; ALT: alanine aminotransferase; AST: aspartate aminotransferase; GGT: gamma glutamyl transferase; ALP: alkalinephosphatase. 
Table 2. Distribution of white blood cell, hemoglobin, platelet, neutrophil, international normalized ratio, C-reactive protein, alanine aminotransferase, aspartate aminotransferase, gamma glutamyl transferase, alkalinephosphatase, amylase, total bilirubin, and direct bilirubin values of patients in the ERCP-PC-applied group (Group II) ( $n=23$ ) based on their single or combined antibiotic treatment status.

\begin{tabular}{|c|c|c|c|c|c|c|c|c|}
\hline \multirow{2}{*}{$\begin{array}{l}\text { Laboratory } \\
\text { results }\end{array}$} & \multicolumn{3}{|c|}{ Single antibiotic $(n=17)$} & \multicolumn{3}{|c|}{ Combined antibiotic $(n=6)$} & \multirow{2}{*}{$\begin{array}{l}\text { Difference } \\
\text { between } \\
\text { changes }\end{array}$} & \multirow[b]{2}{*}{$p$-value } \\
\hline & $\begin{array}{l}\text { First value } \\
\text { (mean) }\end{array}$ & $\begin{array}{l}\text { Last value } \\
\text { (mean) }\end{array}$ & $\begin{array}{l}\text { Change } \\
\text { (mean) }\end{array}$ & $\begin{array}{l}\text { First value } \\
\text { (mean) }\end{array}$ & $\begin{array}{c}\text { Last value } \\
\text { (mean) }\end{array}$ & $\begin{array}{l}\text { Change } \\
\text { (mean) }\end{array}$ & & \\
\hline $\mathrm{WBC}\left(/ \mathrm{mm}^{3}\right)$ & 13.89 & 7.62 & 6.27 & 15.52 & 9.11 & 6.41 & -0.14 & 0.64 \\
\hline Hemoglobin (g/dL) & 13.29 & 11.86 & 1.43 & 13.28 & 11.47 & 1.81 & -0.38 & 0.80 \\
\hline $\mathrm{PLT}(/ \mathrm{dL})$ & 261.65 & 292.59 & -30.94 & 290.83 & 311.33 & -20.50 & -10.44 & 0.14 \\
\hline$\% N E$ & 79.27 & 58.56 & 20.71 & 81.93 & 63.60 & 18.33 & 2.38 & 0.40 \\
\hline INR & 5.96 & 5.28 & 0.68 & 1.16 & 1.23 & -0.07 & 0.75 & 0.56 \\
\hline CRP & 153.76 & 57.50 & 96.26 & 196.13 & 82.39 & 113.74 & -17.48 & 0.76 \\
\hline ALT & 100.00 & 65.41 & 34.59 & 71.50 & 17.17 & 54.33 & -19.74 & 0.39 \\
\hline AST & 90.29 & 47.76 & 42.53 & 56.17 & 24.67 & 31.50 & 11.03 & 0.61 \\
\hline GGT & 150.35 & 136.06 & 14.29 & 91.33 & 73.50 & 17.83 & -3.54 & 1.00 \\
\hline ALP & 123.94 & 160.88 & -36.94 & 104.33 & 93.50 & 10.83 & -47.77 & 0.12 \\
\hline Amylase & 69.47 & 87.53 & -18.06 & 78.00 & 92.67 & -14.67 & -3.39 & 0.76 \\
\hline Bilirubin total & 5.65 & 4.65 & 1.00 & 13.65 & 10.20 & 3.45 & -2.45 & 0.47 \\
\hline Bilirubin direct & 0.72 & 3.02 & -2.30 & 0.55 & 0.18 & 0.37 & -2.67 & 0.92 \\
\hline
\end{tabular}

WBC: white blood cell; PLT: platelet; \%NE: neutrophil; INR: international normalized ratio; CRP: C-reactive protein; ALT: alanine aminotransferase; AST: aspartate aminotransferase; GGT: gamma glutamyl transferase; ALP: alkalinephosphatase.

Table 3. Distribution of white blood cell, hemoglobin, platelet, neutrophil, international normalized ratio, C-reactive protein, alanine aminotransferase, aspartate aminotransferase, gamma glutamyl transferase, alkalinephosphatase, amylase, total bilirubin, and direct bilirubin values of patients in the Medical Treatment group (Group III) $(n=78)$ based on their single or combined antibiotic treatment status.

\begin{tabular}{|c|c|c|c|c|c|c|c|c|}
\hline \multirow{2}{*}{$\begin{array}{l}\text { Laboratory } \\
\text { results }\end{array}$} & \multicolumn{3}{|c|}{ Single antibiotic $(n=59)$} & \multicolumn{3}{|c|}{ Combined antibiotic $(n=19)$} & \multirow{2}{*}{$\begin{array}{l}\text { Difference } \\
\text { between } \\
\text { changes }\end{array}$} & \multirow[b]{2}{*}{$p$-value } \\
\hline & $\begin{array}{l}\text { First value } \\
\text { (mean) }\end{array}$ & $\begin{array}{l}\text { Last value } \\
\text { (mean) }\end{array}$ & $\begin{array}{l}\text { Change } \\
\text { (mean) }\end{array}$ & $\begin{array}{l}\text { First value } \\
\text { (mean) }\end{array}$ & $\begin{array}{c}\text { Last value } \\
\text { (mean) }\end{array}$ & $\begin{array}{l}\text { Change } \\
\text { (mean) }\end{array}$ & & \\
\hline $\mathrm{WBC}\left(/ \mathrm{mm}^{3}\right)$ & 14.48 & 8.35 & 6.13 & 15.76 & 8.13 & 7.63 & -1.50 & 0.63 \\
\hline Hemoglobin (g/dL) & 13.26 & 11.82 & 1.44 & 13.11 & 11.69 & 1.42 & 0.02 & 0.86 \\
\hline $\mathrm{PLT}(/ \mathrm{dL})$ & 261.20 & 274.07 & -12.87 & 258.53 & 251.74 & 6.79 & -19.66 & 0.67 \\
\hline$\% \mathrm{NE}$ & 78.37 & 59.58 & 18.79 & 77.86 & 64.35 & 13.51 & 5.28 & 0.04 \\
\hline INR & 2.70 & 2.61 & 0.09 & 9.41 & 8.38 & 1.03 & -0.94 & 0.02 \\
\hline CRP & 122.11 & 57.11 & 65.00 & 114.99 & 55.30 & 59.69 & 5.31 & 0.61 \\
\hline ALT & 42.03 & 39.58 & 2.45 & 139.84 & 39.63 & 100.21 & -97.76 & 0.05 \\
\hline AST & 42.00 & 29.02 & 12.98 & 146.05 & 29.11 & 116.94 & -103.96 & 0.35 \\
\hline GGT & 93.03 & 93.88 & -0.85 & 68.58 & 77.00 & -8.42 & 7.57 & 0.60 \\
\hline ALP & 116.71 & 109.21 & 7.50 & 101.89 & 90.44 & 11.45 & -3.95 & 0.40 \\
\hline Amylase & 67.39 & 67.81 & -0.42 & 132.26 & 92.32 & 39.94 & -40.36 & 0.40 \\
\hline Bilirubin total & 3.43 & 2.76 & 0.67 & 9.05 & 6.77 & 2.28 & -1.61 & 0.19 \\
\hline Bilirubin direct & 0.29 & 0.17 & 0.12 & 0.46 & 0.20 & 0.26 & -0.14 & 0.40 \\
\hline
\end{tabular}

WBC: white blood cell; PLT: platelet; \%NE: neutrophil; INR: international normalized ratio; CRP: C-reactive protein; ALT: alanine aminotransferase; AST: aspartate aminotransferase; GGT: gamma glutamyl transferase; ALP: alkalinephosphatase. 
is prevalently used at many centers. While selecting antibiotics, it should be kept in mind the potential agent of infection, the allergic or other side-effect history of the patient, and liver and kidney functions of the patients.

It is recommended to keep empirical treatment as short as possible and apply target-oriented treatment by determining the effective antibiotic based on the bile culture and antibiogram results ${ }^{6,12}$. Bacteria cannot be isolated from the bile culture of more than half of patients with AC. For this reason, in order to make the right decision in empirical AT, the results of culture antibiogram performed previously in that region should be considered. The most frequently encountered bacterium in biliary tracts is Escherichia coli. In addition, Gram-negative bacteria like Klebsiella spp, Pseudomonas spp, and Enterobacteria and Gram-positive bacteria like Enterococcus spp and Streptococcus spp are also isolated, and the spectrum of the antibiotics to be selected should cover these microorganisms ${ }^{5,11,13}$.

In addition to bacterial resistance, long-term and high-dose antibiotic use leads to gastrointestinal symptoms such as allergic reactions, nausea, vomiting, and diarrhea and causes some hepatorenal toxicities. It has been shown that long-term and unsuitable AT may increase bacterial resistance three times ${ }^{14}$. These objections are applicable to almost all antibiotics, and avoiding unnecessary use of antibiotics is highly important due to these side effects. Additionally, with combined antibiotic usage, the use of broad-spectrum antibiotics has increased, and this has severely raised the costs of hospitalization. This is why avoiding unnecessary multiple antibiotic usage is also important in terms of hospital and health costs.

With the publication of the Tokyo Guidelines, monotherapies have started to be used at all centers instead of CAT. The effectiveness of AT is measured based on the recovery of the pretreatment clinical, radiological, and laboratory findings. It was seen in randomized clinical studies comparing antibiotics used in AC treatment that there was no significant difference between antibiotics ${ }^{15,16}$. Therefore, it is important to investigate whether or not applying the antibiotics that are used either singly or in combination has any difference in the treatment of the disease.

\section{CONCLUSIONS}

As a result of this study, no significant superiority of CAT over SAT was observed in terms of hospitalization durations, mortality, and reduction in laboratory parameters in both the cholecystectomy group and the medical treatment group, and it was concluded that the use of CAT is not necessary. We recommend that it is sufficient to apply single-dose prophylactic AT in Grade I AC cases, and in the case of more severe disease indicating therapeutic interventions, SAT by selecting the most appropriate antibiotic would be appropriate rather than CAT as it is not disadvantageous in comparison to multiantibiotic usage in terms of reducing treatment costs, bacterial resistance development, potential allergic reactions, hepatorenal toxic effects, and hospitalization durations.

\section{ETHICAL APPROVAL}

The study was conducted at Gulhane Training and Research Hospital and approved by the Ministry of Health of the Republic of Turkey and Republic of Turkey Health Sciences University Gulhane Scientific Research Ethics Committee (dated March 11, 2021, number: 2021/112).

\section{AUTHORS" CONTRIBUTIONS}

ÜA: Conceptualization, Data curation, Formal analysis, Investigation, Methodology, Project administration, Resources, Supervision, Validation, Visualization, Writing - original draft, Writing - review \& editing. YSP: Conceptualization, Data curation, Formal analysis, Investigation, Methodology, Project administration, Resources, Supervision, Validation, Visualization, Writing - original draft, Writing - review \& editing.

\section{REFERENCES}

1. Gomi H, Solomkin JS, Schlossberg D, Okamoto K, Takada T, Strasberg SM, et al. Tokyo Guidelines 2018: antimicrobial therapy for acute cholangitis and cholecystitis. J Hepatobiliary Pancreat Sci. 2018;25(1):3-16. https://doi.org/10.1002/ jhbp. 518

2. Yokoe M, Hata J, Takada T, Strasberg SM, Asbun HJ, Wakabayashi G, et al. Tokyo Guidelines 2018: diagnostic criteria and severity grading of acute cholecystitis (with videos). J Hepatobiliary Pancreat Sci. 2018;25(1):41-54. https://doi.org/10.1002/ jhbp. 515
3. Sawyer RG, Claridge JA, Nathens AB, Rotstein OD, Duane TM, Evans HL, et al. Trial of short-course antimicrobial therapy for intraabdominal infection. N Engl J Med. 2015;372(21):1996-2005. https://doi.org/10.1056/NEJMoa1411162. Erratum in: N Engl J Med. 2018;378(7):686. https://doi.org/10.1056/NEJMx180006

4. La Regina D, Di Giuseppe M, Cafarotti S, Saporito A, Ceppi M, Mongelli F, et al. Antibiotic administration after cholecystectomy for acute mild-moderate cholecystitis: a PRISMA-compliant meta-analysis. Surg Endosc. 2019;33(2):377-383. https://doi. org/10.1007/s00464-018-6498-0 
5. Bari $H$, Khan MR, Shariff AH. Antibiotics in acute calculous cholecystitis - do Tokyo guidelines influence the surgeons' practices? J Pak Med Assoc. 2017;67(5):670-6. PMID: 28507349

6. Miura F, Okamoto K, Takada T, Strasberg SM, Asbun HJ, Pitt HA, et al. Tokyo Guidelines 2018: initial management of acute biliary infection and flowchart for acute cholangitis. J Hepatobiliary Pancreat Sci. 2018;25(1):31-40. https://doi.org/10.1002/jhbp.509

7. Yoshida M, Takada T, Kawarada Y, Tanaka A, Nimura Y, Gomi $\mathrm{H}$, et al. Antimicrobial therapy for acute cholecystitis: Tokyo Guidelines. J Hepatobiliary Pancreat Surg. 2007;14(1):83-90. https://doi.org/10.1007/s00534-006-1160-y

8. Okamoto K, Suzuki K, Takada T, Strasberg SM, Asbun HJ, Endo I, et al. Tokyo Guidelines 2018: flowchart for the management of acute cholecystitis. J Hepatobiliary Pancreat Sci. 2018;25(1):5572. https://doi.org/10.1002/jhbp.516. Erratum in: J Hepatobiliary Pancreat Sci. 2019;26(11):534. https://doi.org/10.1002/jhbp.686

9. McGillicuddy EA, Schuster KM, Barre K, Suarez L, Hall MR, Kaml GJ, et al. Non-operative management of acute cholecystitis in the elderly. Br J Surg. 2012;99(9):1254-61. https://doi.org/10.1002/bjs.8836

10. Lee SO, Yim SK. Management of acute cholecystitis. Korean J Gastroenterol. 2018;71(5):264-8. https://doi.org/10.4166/ kjg.2018.71.5.264

11. van Dijk AH, de Reuver PR, Tasma TN, van Dieren S, Hugh TJ, Boermeester MA. Systematic review of antibiotic treatment for acute calculous cholecystitis. Br J Surg. 2016;103(7):797811. https://doi.org/10.1002/bjs. 10146
12. Mayumi T, Okamoto K, Takada T, Strasberg SM, Solomkin JS Schlossberg D, et al. Tokyo Guidelines 2018: management bundles for acute cholangitis and cholecystitis. J Hepatobiliary Pancreat Sci. 2018;25(1):96-100. https://doi.org/10.1002/ jhbp. 519

13. Yun SP, Seo HI. Clinical aspects of bile culture in patients undergoing laparoscopic cholecystectomy. Medicine (Baltimore). 2018;97(26):e11234. https://doi.org/10.1097/ MD.0000000000011234

14. Sartelli M, Catena F, Ansaloni L, Coccolini F, Corbella D, Moore $\mathrm{EE}$, et al. Complicated intra-abdominal infections worldwide: the definitive data of the CIAOW Study. World J Emerg Surg. 2014;9:37. https://doi.org/10.1186/17497922-9-37

15. Hajibandeh S, Popova P, Rehman S. Extended postoperative antibiotics versus no postoperative antibiotics in patients undergoing emergency cholecystectomy for acute calculous cholecystitis: a systematic review and metaanalysis. Surg Innov. 2019;26(4):485-96. https://doi. org/10.1177/1553350619835347

16. Yellin AE, Berne TV, Appleman MD, Heseltine PN, Gill MA, Okamoto MP, et al. A randomized study of cefepime versus the combination of gentamicin and mezlocillin as an adjunct to surgical treatment in patients with acute cholecystitis. Surg Gynecol Obstet. 1993;177 Suppl:23-9; discussion 35-40. https://doi.org/10.1016/0020-7292(94)90427-8 